\title{
¿Renace el espacio público urbano?
}

\author{
Sergio GARCÍA-DOMÉNECH y Pablo MARTí-CIRIQUIÁN \\ Departamento de Edificación y Urbanismo \\ Universidad de Alicante \\ sergio.garcia@ua.es
}

Recibido: $12 / 09 / 2013$

Aceptado: $14 / 10 / 2013$

\section{Resumen}

La actual crisis económica global parece haber devuelto el protagonismo al espacio público en la ciudad. Por una parte, renace el papel reivindicado del espacio público. Por otra, el uso cívico del mismo se ha intensificado frente a la realidad sesgada de los espacios colectivos privados, predominantes durante los últimos años. A partir de tres episodios recientes de la evolución del espacio público en la sociedad española, este artículo pone en evidencia tres enfoques sobre el mismo: el control político, la reivindicación social y el uso cívico. Tras un posterior periodo de decadencia y predominio de lo privado en la ciudad, la condición ciudadana ha vuelto a impulsar el espacio público como espacio social por excelencia. Se concluye destacando la oportunidad de recuperar el lugar urbano, así como la necesidad de potenciar el rol que el espacio público debe seguir representando en la complejidad de la ciudad.

Palabras clave: espacio público, ciudadanía, control político, reivindicaciones urbanas, civismo.

Title: The rebirth of urban public space?

\section{Abstract}

The current global economic crisis seems to have returned to the role of public space in the cities. First, the claimed role of public space is reborn. In addition, civic use of public space has been boosted in opposite to skewed perception of private collective spaces, prevalent in recent years. Using three recent episodes of the evolution of public space in Spanish society, this article presents three approaches about public space: political control, social claim and civic use. After a period of decline and subsequent dominance of the private in the city, the citizenship status has boosted again the public space as social space par excellence. It concludes by highlighting the opportunity to recover the urban place and the need to enhance the role that public space must continue to play in the complexity of the city.

Keywords: public space, citizenship, political control, urban claims, public spirit.

\section{Índice}

1. Introducción

2. El espacio público controlado

3. El espacio público reivindicado

4. El espacio público cívico

5. El espacio público agonizante

6. A modo de conclusión: ¿renace el espacio público? 


\section{Introducción}

El espacio público ha mantenido diferentes roles en la sociedad urbana. En función de las circunstancias sociales, políticas y económicas de cada momento, se ha constituido en escenario de la representación colectiva en la ciudad. El espacio público puede ser un instrumento de control político, de reivindicación, o también de expresión y afirmación ciudadana. La crisis económica y social global de los últimos años, parece recuperar de nuevo el protagonismo de los espacios públicos especialmente los más representativos- en el organigrama de la ciudad. Las nuevas tecnologías de la comunicación han tenido un papel muy destacado en la constitución y gestión de los nuevos movimientos sociales urbanos, pero los colectivos organizados más activos en todo el mundo siguen optando por el espacio público urbano como lugar de expresión de la ciudadanía. La experiencia urbana es compleja, fundamentalmente por la naturaleza de su principal elemento activo: el ciudadano. El ciudadano no es un sujeto estable y esa inestabilidad revierte en tensión sobre su hábitat colectivo, que es el espacio público (Norberg-Schulz 1975: 22-23). Precisamente, esa tensión humana sobre el espacio urbano es la que lo cualifica:

En el meollo de la estructura de los procesos urbanos está el intercambio social -las transacciones comerciales, los cambios de información, las intrincadas y complejas redes de interacciones- a través de las cuales los ciudadanos tratan entre sí y satisfacen la interdependencia de la cual depende su forma de vida y su bienestar. (Webber 1974: 74)

Ningún recinto cerrado, público o privado, alcanza un nivel de publicidad tan alto como el propio espacio urbano. Las cualidades democratizadoras y no excluyentes que son inherentes al espacio público por definición, se revelan mediante la celebración de interacciones colectivas. ¿Qué mejor lugar de contacto interpersonal y regeneración social que el espacio público urbano? Ésta podría ser la cuestión que nos haga reflexionar sobre la dimensión social del mismo como lugar de encuentro y de ejercicio de los derechos ciudadanos:

El espacio público es el lugar donde todo ciudadano tiene derecho a circular, a estar y hacer [...]. El poder transitar remite a la libertad de movimiento, el poder estar remite a la apropiación del espacio y el poder hacer remite a la participación en el espacio público. Enfatizando este último aspecto nos lleva a la consideración de que el espacio público es siempre un espacio colectivo donde se encuentran los diferentes, los actores diversos, las partes que comparten el espacio y que al hacerlo lo elevan a la categoría de público y colectivo, es decir, los diferentes toman conciencia de la diferencia porque son susceptibles de encontrarse, interactuar y finalmente interaccionar, por ello el compartir el espacio creativamente significa estar en un lugar, ser 
parte, sentirse parte, tomar o tener parte y hacer lugar. En consecuencia, el espacio público, es aquel espacio de propiedad pública, y de dominio y uso público. La propiedad pública infiere un sentido político, el dominio público un sentido cultural y el uso público un sentido social. (Alguacil 2008: 204-205)

La presencia habitual de actividad en un espacio urbano denota el éxito del mismo como lugar de encuentro y como foro ciudadano. Las relaciones interactivas, y no el lugar, son las que constituyen la vida urbana y la urbanidad en sí misma. La variedad de actividades es el parámetro indicativo de la versatilidad de uso con que el espacio público fue concebido. Íntimamente relacionado con el concepto de actividad urbana aparece también el concepto de acto urbano, como suceso singular y concreto celebrado en un espacio público (Alexander et al. 1980: 290). Pero en el espacio público urbano, actividades y actos no siempre han sido una constante en el uso del mismo. Tres episodios de la reciente historia urbana española, asociados a tres experiencias paralelas sobre el espacio público, así parecen atestiguarlo: la necesidad de control durante la dictadura, la reivindicación ciudadana durante la transición y la apuesta cívica de las primeras corporaciones locales democráticas. Posteriormente, con las nuevas corrientes sociales, económicas, culturales y políticas enraizadas en el pensamiento posmoderno, aparecerían nuevas percepciones del espacio público que lo arrimarían poco a poco hacia una espiral agónica de resultados inciertos. Pero los recientes episodios urbanos en casi todo el mundo y particularmente en el conjunto de la sociedad española, han parecido poner en evidencia un nuevo impulso del espacio público como lugar de expresión ciudadana.

\section{El espacio público controlado}

La ciudad, interpretada como polis, es identificada como lugar de la política y del ejercicio del poder. Tanto la arquitectura institucional como el espacio urbano en el que se escenifica han constituido variables para expresar la autoridad política y su ejercicio: "la historia de la arquitectura está frecuentemente inserta en la historia de las ideas y ha sido usada como instrumento poderoso por los gobernantes para reforzar su propia imagen en la mente de sus súbditos" (Elsen 1975: 13). De manera similar a las ideas de Speer en la Alemania nacionalsocialista, que asimilaron el espacio urbano al poder político (Aguirre Martínez 2010: 6), el nuevo régimen surgido tras la Guerra Civil española necesitaba emprender actuaciones urbanas que mostraran el afianzamiento del mismo ante una sociedad dividida entre vencedores y vencidos. La táctica inicial para perseguir este fin sería la construcción de edificios y monumentos significativos desde el punto de vista del nuevo poder instaurado (De Andrés 2004: 161). En su 
materialización, nunca se dejaría de lado el espacio urbano sobre el que se escenificaría la implantación de las piezas urbanas, pero con un sentido más representativo y escenográfico que social: "la arquitectura es empleada por los dirigentes políticos para seducir, impresionar e intimidar" (Sudyic 2007: 6).

Pero si en el periodo inicial del régimen instaurado tras la Guerra Civil la inquietud recaía sobre la representatividad institucional de arquitecturas y monumentos, durante su etapa final ${ }^{1}$ la preocupación derivaría directamente hacia el propio espacio público. Para entonces, el problema ya no era de carácter representativo ni escenográfico, sino sociopolítico. El espacio público urbano, el lugar erigido tradicionalmente para expresar la voluntad ciudadana, representaba permanentemente una amenaza para el orden establecido. Por lo tanto, el control sobre el mismo se habría de convertir en una obsesión de las autoridades políticas. Este control permanecía latente en las aplicaciones e interpretaciones normativas que amparaban la represión, la limitación y el control de todo tipo de reunión asamblearia².

Fuera de la esfera política, dos circunstancias sobrevenidas resultarían aprovechadas coyunturalmente por el régimen para apoyar el control institucional del espacio público: el fenómeno desarrollista experimentado en varias de las ciudades españolas y una de sus principales manifestaciones urbanas: la presencia masiva del automóvil en el paisaje urbano. Durante el desarrollismo económico de los años sesenta y primeros setenta, los aumentos generalizados de altura en tejidos urbanos consolidados -con el consiguiente incremento de la densidad- no conllevaron, por lo común, un aumento proporcional de espacios libres públicos ni en cantidad ni en calidad. Sería una época de construcción masiva y premiosa, en la que los mecanismos públicos de control se verían tan desbordados como incapacitados para planificar adecuadamente los desarrollos urbanos. De esta de forma, la ciudad terminaría por dar la espalda a la necesidad de creación de espacios públicos. De la mano del anterior fenómeno urbano, la progresiva implantación del automóvil en la ciudad también tendría un importante impacto sobre el espacio público. Esto se sentiría especialmente a partir del espectacular aumento de volumen del parque automovilístico

\footnotetext{
${ }^{1}$ Franquismo tardío o tardofranquismo.

${ }^{2}$ Aunque la libertad de reunión y asociación estaban reconocidas en el Art. 16 del Fuero de los Españoles, el Art. 35 amparaba una fácil suspensión temporal de dichas libertades por el Gobierno mediante Decreto-Ley. Además, la Ley de Principios del Movimiento promulgaba que "los intereses individuales y colectivos han de estar subordinados siempre al bien común de la Nación". Argumentando precisamente la defensa del "bien común de la Nación" se suspenderían frecuentemente la mayoría de las libertades individuales y colectivas, entre ellas, la libertad de reunión.
} 
durante los años sesenta. Por su propia naturaleza, vida pública y vehículo privado conforman frecuentemente una antítesis en la ciudad:

El automóvil per se, no tiene nada de malo. Lo malo es el uso exagerado que hacemos de él. Constituyendo esencialmente una comodidad privada, sin embargo viola con excesiva frecuencia los intereses públicos [...]. El automóvil impide inclusive caminar. (Chermayeff y Alexander 1968: 88)

Para dar cabida a la demanda de estacionamiento público, especialmente en los centros urbanos consolidados, la tutela centralista del Estado induciría a las administraciones locales a la promoción del aparcamiento en las plazas públicas. Estas actuaciones traerían como consecuencia un profundo impacto urbano sobre el espacio público que se evidenciaría en cualquiera de sus dos opciones: estacionar en el suelo o en el subsuelo. En el primer caso, el impacto sería directo y presencial, al emplear las plazas públicas como playas de aparcamiento en superficie. En el segundo caso, las consecuencias para el espacio público serían aparentemente más sutiles, pero no menos dramáticas: desaparición total o presencia testimonial de la vegetación, aumento de la pavimentación y endurecimiento urbano, protagonismo de la circulación rodada, ruptura de la continuidad peatonal y limitación de la accesibilidad al espacio público. Pero si hacemos una lectura política de ello, aparecen criterios de control urbano: las plazas y calles, ocupadas permanentemente por automóviles, dificultarían las reuniones ciudadanas y enajenarían el sentido político del espacio urbano. Para la política nacional de orden público del momento, los criterios municipales de rendir el espacio público al automóvil privado ${ }^{3}$, que se convertiría en protagonista de calles y plazas, no serían mal vistos desde la administración central. Es esta una circunstancia que si no causal, sería al menos coyuntural para limitar la ocupación ciudadana del espacio público y consecuentemente ejercer un mejor control político del mismo.

\section{El espacio público reivindicado}

El temor de las instituciones políticas a perder el control de la ciudadanía, se iría diluyendo poco a poco tras la normalización democrática y una paulatina recuperación de la cultura del espacio público. Las nuevas políticas urbanas, especialmente las ejercidas por las instituciones de alcance local ${ }^{4}$, potenciarían y abogarían por el uso de calles y plazas para la celebración de todo tipo de actos y

\footnotetext{
${ }^{3}$ En el contexto del desarrollismo, al igual que el alarde tecnológico del edificio en altura, la promoción del automóvil privado sería empleado frecuentemente como sofisma en nombre de la modernidad.

${ }^{4}$ A partir de los primeros comicios democráticos municipales de 1979.
} 
actividades ciudadanas, con una especial implicación de las asociaciones de vecinos como colectivos pioneros en la recuperación de la ciudad por parte de los ciudadanos:

La urbanización acelerada de los años 60 no fue acompañada de las inversiones paralelas en equipamientos e infraestructuras, y al filo de los años 70 es también cuando comienzan a aparecer las primeras Asociaciones de Vecinos reivindicando la mejora de las condiciones de vida urbana, exigiendo que las ciudades sean realmente 'ciudades'. (Fernández Alba y Gavira 1986: 104)

Al inicio de la Transición, la reivindicación social urbana abarcaría tres frentes. En primer lugar, existía una carencia generalizada de espacios públicos urbanizados, sobre todo en los barrios de inmigración surgidos a tenor del desarrollismo, en los que la urgencia habitacional requería de una rápida construcción que no repararía en las más esenciales necesidades dotacionales y colectivas. En segundo lugar, existía un importante interés participativo ciudadano que encontraría su reflejo tanto en las frecuentes asambleas ciudadanas (Laraña Rodríguez-Cabello 2011: 63-68), como en la intención de involucrarse lo más directamente posible en los procesos urbanos: "La participación popular directa en el planeamiento y en la gestión local de la administración mediante consejos de vecinos que toman decisiones ejercitando la democracia directa se presenta como una alternativa valiosa" (García-Bellido y González Tamarit 1979: 167). Y es que la participación en materia urbana podía tener un doble sentido: la simple democratización de los mecanismos para canalizar la voluntad social y el urbanismo participado directamente por los ciudadanos que diseñan su propio medio ambiente:

Empecemos por preguntarnos con exactitud qué significa 'participar'. Puede significar cualquier tipo de proceso a través del cual los usuarios ayuden a diseñar su medio ambiente. La forma más modesta de participación sería entonces la del usuario que es meramente el cliente de un arquitecto. Y la forma más completa de participación sería la del usuario que construye realmente su propio medio ambiente por sí mismo. (Alexander 1976: 31)

Finalmente, en tercer lugar, surgirían nuevas necesidades ciudadanas como consecuencia directa de los inminentes cambios políticos y sociales que se avecinaban: la democratización de las instituciones públicas, la recuperación del control social sobre el espacio público urbano y las esperanzas depositadas en la participación urbana como mecanismo socializador de la ciudad:

Este es, en efecto, un terreno crucial, en el que se va a jugar, en gran medida, no sólo el futuro del urbanismo español, sino también en 
parte, el de la democracia en este país. Por eso es necesario predicar y promover una amplia incorporación social al proceso de reflexiónparticipación que la evolución política reclama para un nuevo entendimiento de la actividad planificadora. (De Terán Troyano 1978: 623-624)

Un ejemplo material de todo esto lo constituye el hecho de que casi todas las urbanizaciones de nuevas plazas públicas en los barrios de inmigración ${ }^{5}$ harían previsión de un lugar específico donde poder celebrar actos diversos. En ese sentido, una tendencia funcional en la urbanización de los espacios públicos de esta época sería la construcción de podios, frecuentemente solicitados a los proyectistas por las asociaciones de vecinos en toda actuación o intervención sobre el espacio público. Se evidenciaba la necesidad social de disponer, en un momento dado, de un lugar en el que los dirigentes vecinales pudieran informar, debatir e incluso arengar al colectivo para potenciar actitudes reivindicativas ante las autoridades locales. Era como si se deseara, de forma un tanto idealizada, racionalizar el uso del espacio público como lugar de acción ciudadana. Estos elementos, que en parte funcionarían como púlpitos laicos, facilitarían un mecanismo participativo para la puesta en común de los problemas urbanos, ejemplificando la fusión entre espacio público y espacio político:

La participación, en consecuencia, es el nexo que asocia lo público (diversidad de actores) y lo político (estrategia de puesta en común entre los actores), y ello tiene su plasmación en el territorio, ya que la organización del mismo y la ordenación de las relaciones que soporta son inherentemente políticas. Pero, además, el espacio público y el espacio político se solapan, se confunden, se fusionan. Precisamente el nexo de unión entre uno y otro conforma la polis, la ciudad originaria. (Alguacil 2008: 204)

Por otra parte, conviene aclarar que la ciudadanía percibía de manera diferente los espacios públicos de los centros urbanos frente a los planificados en los nuevos barrios residenciales. La explicación puede estar amparada en la propia percepción social de los centros urbanos: tradicionalmente, el centro de la ciudad ha sido el testigo de su evolución, el espejo donde se han reflejado todos sus avatares y donde los habitantes de la ciudad han conseguido dinamizar más la vida de la urbe. No tiene por qué tener forma geométrica ni posición geográfica, sino interacción social. Teorías cercanas a ese contexto cronológico definirían el centro urbano como una "agregación de actividades en torno a un punto de la ciudad" (Webber 1974: 126127), o como "el lugar donde se concentra la mayor densidad de

\footnotetext{
${ }^{5}$ Además de los más reivindicativos por las carencias dotacionales, al mismo tiempo serían los más abiertos a las nuevas concepciones de diseño.
} 
actividades de dirección y coordinación de la ciudad" (García-Bellido y González Tamarit 1979: 64-65). Por lo tanto, si asimilamos el centro urbano a una agrupación de actividades, estamos estableciendo un flujo interactivo entre sus habitantes. De esta forma, el contacto interpersonal se debería erigir como condición indispensable para vitalizar el centro de la ciudad. Sin embargo, en las plazas públicas de los centros urbanos, algo estaba fallando. Los que deberían confirmarse como espacios que debían identificar a la ciudad, paradójicamente acababan cayendo en el más puro abandono social con demasiada frecuencia, con lo que esa identidad del centro urbano se difuminaría a la par que sus espacios públicos más significativos.

Por el contrario, en los nuevos barrios residenciales, ocurría un fenómeno diferente. El urbanita, el habitante de la urbe -urbs-, posee una necesidad casi intuitiva de identificar la zona en la que vive y de convertirse en ciudadano, en generador de ciudad -civitas-: "La gente necesita pertenecer a una unidad espacial identificable [...]. Las personas desean ser capaces de identificar aquella parte de la ciudad en que viven, como algo distinto a todas las demás" (Alexander et al. 1980: 95). El concepto de barrio está ligado a una zona de la ciudad con identidad propia, con personalidad claramente percibida tanto por sus habitantes como por sus visitantes (Moreno González 2013: 96), así que en la conformación de esa identidad, las componentes sociales juegan un importante papel. En ese sentido, los barrios inmigratorios de la época, fuertemente empujados por el deseo de conseguir su propia identidad respecto el centro urbano, participarían más activamente en la conformación y definición de sus espacios públicos. La ausencia de señas de identidad histórica y topológica en los nuevos tejidos urbanos impulsaría a que el vecindario de los mismos potenciara la participación y la reivindicación como estandarte social del momento.

\section{El espacio público cívico}

Lo civil es lo que pertenece a la ciudad o a los ciudadanos: la civitas de la cultura clásica occidental, como modelo de ciudad socialmente avanzada (Borja y Muxí 2003: 105-106). Por el contrario, entendemos por incivil lo carente de civilidad, de cultura en sentido amplio. Para constituir ciudad es fundamental la actitud cotidiana de sus habitantes. Hablamos de actitud cívica cuando es éticamente positiva y nos referimos a la conducta incívica cuando es moralmente reprochable. El civismo implica respeto a la ciudad, a su uso y a la convivencia con los demás ciudadanos. Este término social, ético y cultural se mantiene en los fundamentos de la ciencia urbana. Los conceptos de urbanismo y urbanidad comparten similar etimología: se entiende que el conjunto de normas de educación y respeto en la convivencia social son práctica común de la condición ciudadana, condición que en definitiva, es la responsable de crear ciudad. La ciudad no hace ciudadanos. Al 
contrario: son los ciudadanos, con su conjunto de normas de respeto a la convivencia social -urbanidad- los que terminan por redefinir una simple aglomeración humana -urbs- como ciudad -civitas- con todas sus consecuencias. La urbanidad es un código de conducta aplicable tanto a la esfera de lo privado como de lo público, pero lo cierto es que en el ámbito público, que es donde se debe saber estar, es donde más convendría su aplicación. Y el lugar más representativo de la dimensión pública de la ciudad es, precisamente, su espacio público (Borja 2003: 25-29). Conforme se consolidaban los nuevos mecanismos democráticos de la sociedad española, las administraciones locales impulsarían políticas de recuperación del espacio público tanto en el sentido material como en el social. Constituidas las nuevas corporaciones municipales democráticas, poco a poco la creación, urbanización y mejora de los espacios públicos sería una constante en todas las ciudades españolas para impulsar la imagen política:

Para entender lo que ha caracterizado el concepto de espacio público en las actuaciones llevadas a cabo en España durante estos quince últimos años [1975-1990], deberíamos acaso remontarnos a la situación social que hemos vivido durante ese período de tiempo. No hay que olvidar que en el año $1975[\ldots]$, tiene lugar el inicio del proceso que desembocará en la consecución de un sistema político democrático, y por lo tanto a un cambio en los poderes públicos que será determinante en la construcción de la ciudad [...]. Si durante la fase terminal del régimen anterior, se produjo un intencionado silenciamiento, tanto de lo que pudiera entenderse como imagen colectiva, como de las iconografías del poder, los nuevos poderes públicos sentirán la imperiosa necesidad de construir una imagen en la que reconocerse, en la que apoyarse dentro del nuevo juego político. (Zaera 1992: 126127)

En la esfera social, sería frecuente la celebración de actos simbólicos de posesión sobre el espacio público urbano para demostrar a las instituciones políticas del momento que el uso de estos espacios cívicos correspondía a la ciudadanía. Estos episodios no dejarían de ser una reivindicación del derecho a la vida urbana, como parte del "derecho a la ciudad" (Lefebvre 1969: 167). Las ciudades españolas habían comprendido que los procesos urbanos afectaban directamente al ciudadano medio. Por lo tanto resultaba conveniente emprender una labor de control de técnicos y políticos, sobre sus actuaciones y responsabilidades en materia urbana. La solución sería llevar el urbanismo al debate ciudadano, a la propia calle; y el medio, el asociacionismo vecinal (Gómez Bahillo 2006: 45-48). Las asociaciones de vecinos marcarían una época singular en el ejercicio del civismo hasta su crisis y paulatina deriva de sus dirigentes hacia las incipientes formaciones políticas. 
Volvamos a revisar el hecho de que los barrios inmigratorios más periféricos y desvinculados de la ciudad habían sido levantados con mucha rapidez durante el periodo desarrollista, por lo que solían presentar graves carencias dotacionales y de servicios urbanos (Fernández Alba y Gavira 1986: 104) y además, estaban integrados por un perfil sociolaboral predominantemente obrero. Estas circunstancias serían un inmejorable caldo de cultivo para que eclosionaran las primeras asociaciones de vecinos exigiendo las necesidades urbanas de las que carecían o cuanto menos, adolecían. Estos colectivos que paulatinamente se iban constituyendo, promovían una toma de conciencia ciudadana entre cuyas reivindicaciones básicas figuraba la participación directa y activa en el urbanismo, especialmente en lo concerniente a la creación y urbanización de plazas públicas urbanas. Esta iniciativa sería plausible, pero el desconocimiento del usuario en materia de diseño urbano constituía el problema de la participación activa. La recuperación del espacio público a partir de la reinstauración democrática y el mantenimiento de su simbolismo político, inducirían a pensar que la definición física del mismo también debía de ser una competencia pública directa, decidida en asamblea y por consenso. Para combatir las limitaciones formativas del usuario participante, un mecanismo frecuente sería la canalización de los criterios de diseño del espacio público a través de profesionales de confianza en representación de la voluntad de los colectivos vecinales. Estos profesionales harían de intermediarios entre los mismos y los autores de los proyectos, ejemplificando lo que se ha denominado "participación dialéctica" (Bohigas 1985: 185), de forma que la participación ciudadana definiría el programa funcional, los significados y las prioridades, pero nunca el resultado material del proyecto del espacio público, es decir, los vecinos exponían el qué, pero nunca el cómo, sin renunciar a un claro ejercicio de creación de ciudad y, por lo tanto, de actitud cívica.

\section{El espacio público agonizante}

El individualismo, el predominio de lo privado sobre lo público, el pragmatismo o las dinámicas de la mutación y el cambio constante, son algunos de los resultados del pensamiento posmoderno (Jameson 1995: 101-109; Lyotard 1999: 25-26; Amendola 2000: 88-93; Verdú 2001: 93-97; Sequera y Janoschka 2012: 517-518). Sobre esta base se han asentado dos consecuencias que han reconfigurado el panorama social de la ciudad: en primer lugar, la proliferación por toda Europa, a partir de la década de los ochenta del pasado siglo, de modelos urbanos de crecimiento residencial basados en el predominio del espacio privado sobre el público (Rogers y Gumuchdjian 2000: 9-10). Estos modelos, caracterizados por el aislamiento del individuo frente a la sociedad, tendrían un origen importado del formato suburbano anglosajón -eminentemente norteamericano-, inadaptado a la cultura 
urbana de espacio público y ciudad compacta propia de la Europa mediterránea.

Promueven la vivienda unifamiliar aislada frente a otras tipologías colectivas y limitan el espacio público a la simple vialidad. En ésta, predomina la rodada respecto a la peatonal -total o casi inexistente- y los vehículos privados frente a los sistemas de transporte público. De esta manera, el espacio público urbano entraría en una crisis, potenciada por la segunda de las consecuencias: la aparición y proliferación de los paradójicos "espacios públicos privatizados" (Amendola 2000: 270-276; Borja 2003: 205-206; Borja y Muxí 2003: 39-41; Németh 2012: 2) materializados en forma de grandes complejos comerciales y de ocio ${ }^{6}$.

En ese doble juego de islotes privados, las calles dejarían de serlo para convertirse en simples viales, en los que desaparecería todo atisbo de "adherencia urbana"7 (Demorgon 1991: 48-53). Se abandonaría todo el carácter funcional, histórico, social, cultural y patrimonial (Llull 2005: 179-182) que debería caracterizar a todo espacio público, para convertirse en un simple espacio de paso y no de encuentro. En algunos casos, se llegaba al absurdo urbano de crear de nuevas zonas verdes ${ }^{8}$ desiertas al uso, mientras se observaba la degradación paulatina de los espacios históricos. Un espacio público inactivo y abandonado se degrada tanto física como funcionalmente, facilitando que su entorno se convierta en un "instant slum" (Amendola 2000: 322), haciendo su aparición el miedo social a la ciudad: temor a la inseguridad, a la mezcla con lo diferente, al espacio público y, por lo tanto, a la ciudad en sí misma. De nuevo la calle y la plaza, percibidas como lugares amenazantes y peligrosos, podían ser evitadas a través del automóvil. El automóvil es un invento moderno, pero en la mentalidad posmoderna su interpretación evoluciona como un ejemplo más de "sistema urbano cerrado" (Rogers y Gumuchdjian 2000: 9-11). Si durante los años sesenta y setenta el automóvil constituía un alarde de modernidad con utilidad para controlar

\footnotetext{
${ }^{6}$ En inglés Shopping Centers, Shopping Malls o Malls a secas.

7 Para Demorgon, una calle produce una relación constante de fricción con el entorno, creando adherencia urbana, es decir, la posibilidad de desplazarnos y de acceder a edificios y actividades a lo largo del eje, lo que crea una riqueza de interacciones. Sin embargo, la singularidad de la vialidad rodada privada elimina esas fricciones, que se limitarían exclusivamente a los puntos de salida y llegada.

8 Como término funcional y positivista, habitual en los discursos políticos del momento, estaba asociado a criterios legalistas de simple cumplimiento de los estándares normativos en los desarrollos urbanos dispersos.

${ }^{9}$ Con este concepto, en el lado opuesto de la gentrificación o elitización urbana, Amendola hace alusión a la aparición de un gueto instantáneo: la desocupación del espacio público y entorno residencial los habitantes de origen y su posterior ocupación por otras capas sociales potencialmente conflictivas, proceso que termina por desplazar, no sólo a los residentes, sino también al general colectivo ciudadano.
} 
políticamente el espacio público, a partir de los años ochenta, el automóvil evolucionaría como alarde de posmodernidad, al servicio del individualismo, la privacidad urbana y la anulación de la función social del espacio público, aliviando los miedos urbanos. Esta proliferación de variables de control privado de la ciudad, de los nuevos modos de vida suburbanos y de miedo al espacio público, derivarían en una paulatina fase de agonía del mismo prolongada hasta el momento.

\section{A modo de conclusión: ¿̇renace el espacio público?}

El buen funcionamiento del espacio urbano es el reflejo de una sociedad proclive a la vida pública. En ese sentido, la actual situación de crisis en el mundo occidental, unida a otras circunstancias en distintas partes del mundo ${ }^{10}$, ha derivado en una reacción social que toma el espacio público como centro activo y como campo de operaciones por excelencia. La toma de plazas y otros espacios urbanos se ha prodigado por todo el mundo, particularmente en España, donde la iniciativa del movimiento 15-M ocupando la Puerta del Sol en Madrid, sería seguida en ciudades como Barcelona, Valencia, Sevilla, Alicante, Granada y muchas otras, siempre bajo similares premisas de cambio y reivindicación de la noción de espacio público:

Esta crisis urbana y los graves riesgos de fractura social que conlleva pueden abrir posibilidades para un verdadero cambio de rumbo. Los conflictos, resistencias y malestares anuncian que la crisis es también una oportunidad de cambio, de reinvención del espacio público y sus usos, y una gran oportunidad para recuperar el 'derecho a la ciudad' y para el desarrollo de una democracia urbana. (García-Hípola y Beltrán Rodríguez 2013: 8)

La limitación de la condición pública del espacio urbano, bien sea por mecanismos políticos (García-Hípola y Beltrán Rodríguez 2013: 18), bien por la mercantilización (Németh 2012: 1-4), estaba siendo un hecho durante las últimas décadas, pero la reacción social tampoco tardaría en aparecer. Desde comienzos del siglo XXI, ya estábamos experimentando ciertos indicios de cambio en el espacio público:

Se vive un momento en que la calle vuelve a ser reivindicada como espacio para la creatividad y la emancipación, al tiempo que la dimensión política del espacio público es crecientemente colocada en el centro de las discusiones en favor de una radicalización y una generalización de la democracia. (Delgado 1999: 19)

${ }^{10}$ Por ejemplo, la denominada primavera árabe, aunque coincide en algunos de sus planteamientos con los movimientos ciudadanos del mundo occidental, tiene otras causas derivadas de particulares circunstancias sociales y políticas. 
Los actuales episodios sociales de ocupación colectiva que reflejan la apropiación ciudadana del espacio público suponen un claro ejercicio constitutivo de "espacio ciudadano" (Tamayo 2006: 32). Hay que tener en cuenta que el urbanita también es un sujeto político que necesita ejercitar actos democráticos. Para llevar a cabo ese ejercicio, se requiere un espacio físico que sirva como lugar de expresión: el espacio público se convierte en ese lugar. En ese sentido, los recientes episodios de ocupación del espacio público por los movimientos sociales urbanos han contribuido a potenciar la perspectiva solidaria y moral colectiva en las principales plazas públicas de las ciudades. La recuperación de la condición ciudadana, pasa indefectiblemente por su reintegración en la esfera política:

Así, cuestiones como la solidaridad entre ciudadanos con fundamentos individualistas, el modo de integración normativa (ética o jurídica) de una comunidad política o la forma de hacer compatibles los derechos individuales sin prescindir de objetivos colectivos son aspectos que marcan las pautas sobre los modos de relación entre el individuo y la sociedad política o, dicho de otra manera, la forma de encarar los distintos modelos de ciudadanía. (Anchustegui Igartua 2012: 186)

La concentración humana de sociedades avanzadas es a la vez causa y efecto de la producción de riqueza, conocimiento, trabajo, bienestar, apoyo social, cultura, información, comunicación y un largo etcétera, cuya compilación redunda en la aparición de la condición ciudadana y ésta, a su vez, en la alimentación del ego de la ciudad. Una ciudad no puede entenderse como simple agregación de barrios o zonas cosidas por calles, ni como un conjunto de arquitecturas dispersas más o menos afortunadas, ni como una sucesión de elementos patrimoniales históricos; ni siquiera puede considerarse como una sucesión de espacios públicos interesantes. Una ciudad es una experiencia colectiva e interactiva entre ciudadanos sobre un lugar con identidad. Esa experiencia social es compleja y está repleta de dificultades: desarrollos, crecimientos, transformaciones formales, económicas y sociales, carencias, sobreexplotaciones, obsolescencias, evolución de las necesidades y también de los deseos. Todas estas circunstancias se han presentado en forma de exabruptos a lo largo del historial urbano y su predicción no resulta fácil.

El objetivo final de un espacio público -más allá de su funciónes ser identificado como tal por sus usuarios, alcanzar carácter propio, conseguir hacerse acreedor de su aceptación ciudadana y parte intrínseca de la ciudad. El alcance de ese objetivo -al igual que ocurre en la globalidad de la ciudad- es el resultado de una compleja amalgama de variables sociales, históricas, políticas, económicas y culturales. En el espacio público, la actitud crítica de la ciudadanía resulta tan importante como necesaria para alcanzar una sociedad 
urbana avanzada. Su manipulación con fines partidistas o gregarios, conduce a transformar al ciudadano pensante y crítico en una pieza manipulable para conseguir objetivos particulares, casi siempre de carácter más político y económico que cívico y social. El peligro estriba en que se puede acabar por convertir a la ciudadanía en una simple masa de residentes, habitantes o pobladores, indiferentes a sus propias necesidades pero anhelantes de unos presuntos deseos propios que pueden haber sido creados y dirigidos por terceros: cuando se despoja a la ciudadanía de una mínima formación crítica o de la posibilidad de acceso a la misma, resulta fácil el empleo de argumentos más o menos demagógicos -siempre de fácil asimilación-, para movilizar a una masa receptiva hacia cualquier causa tutelada por otros intereses.

Las actitudes, percepciones y actuaciones, tanto políticas como sociales, sobre el espacio público han presentado ciertos paralelismos históricos: en la primera mitad de la década de los treinta -con el trasfondo de la crisis económica global surgida a raíz del crack de 1929- las políticas locales impulsarían notablemente la regeneración de las plazas y calles existentes; más de cuarenta años después, a finales de los setenta del pasado siglo -ahora en el marco de una nueva recesión económica como consecuencia de la crisis del petróleo de 1973- los poderes locales apostarían de nuevo por una similar política urbana, reforzada en este caso por las especiales circunstancias derivadas del contexto sociopolítico de la Transición Democrática. Tras un nuevo ciclo de cuarenta años, ahora a comienzos de la segunda década del siglo XXI, una nueva y profunda crisis económica requiere volver a emplear el espacio público como instrumento político y como mecanismo de expresión ciudadana. En tiempos de crisis se impone el cuidado y mantenimiento de la ciudad existente, mientras que en momentos de empuje económico se impone el desarrollo y la expansión. La preocupación por lo público en la ciudad -y el espacio público es su lugar físico- encuentra en las crisis económicas, políticas y sociales su mejor laboratorio de ensayo.

\section{Bibliografía}

AGUIRRE MARTÍNEZ, Guillermo (2010): "La arquitectura en el Tercer Reich" [en línea]. Ángulo Recto. Revista de estudios sobre la ciudad como espacio plural, vol. 2, núm. $1 . \quad$ En: http://www.ucm.es/info/angulo/volumen/Volumen02-1/articulos04.htm [Consulta: 30/05/13].

ALEXANDER, Christopher (1976): Urbanismo y participación. Traducción de Josep Muntañola i Thornberg. Barcelona: Gustavo Gili.

-; ISHIKAWA, Sara; y SILVERSTEIN, Murray (1980): Un lenguaje de patrones. Ciudades, Edificios, Construcción. Traducción de Justo G. Beramendi. Barcelona: Gustavo Gili.

ALGUACIL, Julio (2008): "Espacio público y espacio político. La ciudad como el lugar para las estrategias de participación". Revista Polis, vol. 7, núm 20, pp. $199-223$. 
AMENDOLA, Giandomenico (2000): La ciudad postmoderna. Magia y miedo de la metrópolis contemporánea. Traducción de Marisa García Vergaray y Paolo Sustersic. Madrid: Celeste.

ANCHUSTEGUI IGARTUA, Esteban (2012): "Ciudadanía e integración: los derechos sociales y la integración". Co-herencia, vol. 9, núm. 16, pp. $185-211$.

BOHIGAS, Oriol (1985): Reconstrucció de Barcelona. Barcelona: Edicions 62.

BORJA, Jordi (2003): La ciudad conquistada. Madrid: Alianza.

-; y MUXÍ, Zaida (2003): El espacio público. Ciudad y ciudadanía. Barcelona: Electa.

CHERMAYEFF, Serge; y ALEXANDER, Christopher (1968): Comunidad y privacidad. Traducción de Rubén Massera. Buenos Aires: Nueva Visión.

DE ANDRÉS, Jesús (2004): "Las estatuas de Franco, la memoria del Franquismo y la Transición Política Española". Historia y Política, núm. 12, pp. 161-186.

DE TERÁN TROYANO, Fernando (1978): Planeamiento urbano en la España contemporánea. Historia de un proceso imposible. Barcelona: Gustavo Gili.

DELGADO, Manuel (1999): El animal público. Barcelona: Anagrama.

DEMORGON, Marcelle (1991): "Le paysage routier et commercial des banlieues parisiennes; la route et l'établissement humain". Annales de la recherche urbaine, núm. 50, pp. 47-56.

ELSEN, Albert E. (1975): La arquitectura como símbolo de poder. Traducción de $M^{a}$ del Pilar Ganose de Altabella. Barcelona: Tusquets.

FERNÁNDEZ ALBA, Antonio; y GAVIRA, Carmen (1986): Crónicas del espacio perdido. La destrucción de la ciudad en España 1960-1980. Madrid: MOPU.

GARCÍA-BELLIDO, Javier; y GONZÁLEZ TAMARIT, Luis (1979): Para comprender la ciudad. Claves sobre los procesos de producción del espacio. Madrid: Nuestra Cultura.

GARCÍA-HÍPOLA, Mayka; y BELTRÁN RODRÍGUEZ, María (2013): "Acción vs Representación: el 15-M y su repercusión en la ciudad" [en línea]. Ángulo Recto. Revista de estudios sobre la ciudad como espacio plural, vol. 5, núm. 1, pp. 5-26. En: http://www.ucm.es/info/angulo/volumen/Volumen05-1/articulos01.htm Doi: $\quad$ http://dx.doi.org/10.5209/rev ANRE.2013.v5.n1.42065 [Consulta: 30/05/13]

GÓMEZ BAHILLO, Carlos (2006): "Organizaciones vecinales y participación ciudadana". RIO. Revista Internacional de Organizaciones, núm. 0, pp. 45-64.

JAMESON, Fredric (1995): El posmodernismo o la lógica cultural del capitalismo avanzado. Traducción de José Luis Pardo. Barcelona: Paidós.

LARAÑA RODRÍGUEZ-CABELLO, Enrique (2011): "Los movimientos sociales y la transición a la democracia en España", en Rafael QuirosaCheyrouze y Muñoz (ed.), La sociedad española en la Transición. Los movimientos sociales en el proceso democratizador. Madrid: Siglo XXI.

LEFEBVRE, Henri (1969): El derecho a la ciudad. Traducción de J. GonzálezPueyo. Barcelona: Edicions 62. 
LLULL, Josué (2005): "Evolución del concepto y de la significación social del patrimonio cultural". Arte, Individuo y Sociedad, vol. 17, pp. 175204.

LYOTARD, Jean-François (1999): La posmodernidad explicada a los niños. Traducción de Enrique Lynch. Barcelona: Gedisa.

MORENO GONZÁLEZ, Ascensión (2013): "La cultura como agente de cambio social en el desarrollo comunitario". Arte, Individuo y Sociedad, vol. 25, núm. 1 , pp. 95-110. Doi: http://dx.doi.org/10.5209/rev ARIS.2013.v25.n1.41166

NÉMETH, Jeremy (2012): "Controlling the Commons: How Public Is Public Space?". Urban Affairs Review, vol. 48, pp. 811-835. Doi: http://dx.doi.org/10.1177/1078087412446445

NORBERG-SCHULZ, Christian (1975): Existencia, espacio y arquitectura. Traducción de Adrián Margarit. Barcelona: Blume.

ROGERS, Richard; y GUMUCHDJIAN, Philip (2000): Ciudades para un pequeño planeta. Traducción de Miguel Izquierdo y Carlos Sáenz de Valicourt. Barcelona: Gustavo Gili.

SEQUERA, Jorge; y JANOSCHKA, Michael (2012): "Ciudadanía y espacio público en la era de la globalización neoliberal". Arbor. Ciencia, Pensamiento y Cultura, vol. 188, núm. 755, pp. 515-527. Doi: http://dx.doi.org/10.3989/arbor.2012.755n3005

SUDYIC, Deyan (2007): La arquitectura del poder. Traducción de Isabel Ferrer Marrades. Barcelona: Ariel.

TAMAYO, Sergio (2006): "Espacios de ciudadanía, espacios de conflicto". Sociológica, vol. 21, núm. 61, pp. 11-40.

VERDÚ, Vicente (2001): "La sociedad americana ¿sociedad del futuro?", en Juan Pecourt García (dir.), Ciudad para la sociedad del siglo XXI, pp. 81-97. Valencia: Ícaro.

WEBBER, Melvin M. (1974): "El lugar urbano y el dominio urbano ilocal", en Melvin M. Webber et al., Indagaciones sobre la estructura urbana, pp. 73-140. Traducción del Laboratorio de Urbanismo ETSAB. Barcelona: Gustavo Gili.

ZAERA, Alejandro (1992): "Entre la simulación y la conexión. El espacio público en la contemporaneidad", en Alejandro Zaera et al., Arquitectura española contemporánea 1975-1990, pp. 126-127. Madrid: El Croquis Editorial. 